Filipina T. Cevallos-Schnabel, MD, MPH ${ }^{1,2,3}$

'Department of Otolaryngology Head and Neck Surgery East Avenue Medical Center

2 Department of Surgery, Capitol Medical Center

Department of Otolaryngology Head and Neck Surgery Faculty of Medicine and Surgery,

University of Santo Tomas
Correspondence:

Filipina T. Cevallos-Schnabel, MD, MPH

Rm. 1102 Capitol Medical Center

Scout Magbanua cor. Panay Ave, Q.C.

Philippines 1103

Phone : (632) 372-3825 loc 5102

Email : pincevallosmd@yahoo.com

Reprints will not be available from the author.

No funding support was received for this study. The author signed a disclosure that she has no proprietary or financial interest with any organization that may have a direct interest in the subject matter of this manuscript, or in any product used or cited in this article.

\section{An Easy Guide for Voice Evaluation in the Clinic}

The past three years have seen an overwhelming increase in the number of dysphonic patients in our clinics. This phenomenon goes hand in hand with increased opening of call centers nationwide and increased demand for teachers, singers and performers abroad.

This article discusses simple steps for the Otolaryngologist interested in evaluating these patients with different voice demands. It is important to recognize these common voice problems and address them promptly, or to refer them accordingly to Voice Centers if necessary.

\section{Chief Complaint}

The most common chief complaint is change in the quality of the voice or hoarseness. Hoarseness means a change in the perception of one's voice, described as harsh, raspy, "paos" or "malat." Other complaints include breathiness, throat pain, neck pain, inability and unrealibility to reach high notes.

Inability to reach high notes suggests edema of the vocal folds making them more plump, as can be found in reflux laryngitis, allergies or smoking. Lesions such as nodules, polyps and cysts cannot be discounted because they prevent vocal fold closure especially during high notes.'

Throat and neck pain without an accompanying history of infection may suggest muscle tension dysphonia, especially in a voice professional who later develops maladaptive ways of talking that could strain other throat and neck muscles in an effort to speak. ${ }^{2}$

Frequent throat clearing, a sensation of phlegm in the throat and cough are also important chief complaints that may lead the otolaryngologist to the cause of the voice problem. In the absence of upper respiratory tract infections and post-nasal discharge, these could be suggestive of laryngopharyngeal reflux. ${ }^{3}$

\section{History}

Does the hoarseness occur on and off? Was it sudden? After shouting in a basketball event? Is it becoming worse and permanent? What triggers or relieves it?

Intermittent hoarseness could be due to voice abuse and misuse especially in a voice professional. Sudden hoarseness especially after watching a basketball event could be suggestive of vocal fold hemorrhage. A voice problem becoming worse and permanent could be a growing polyp or cyst, vocal fold paralysis in laryngeal cancer or thyroid cancer. A long lecture triggering the hoarseness and rest relieving it may suggest soft nodules, or Reinke's edema due to vocal fold trauma of voice abuse and misuse.

To begin with, it is important to know the occupation of our patient. Is our patient a voice professional- someone who uses his or her voice for a living? Voice demands at work contribute to voice change significantly and voice abuse and misuse is one of the most common causes of hoarseness. What are the other associated symptoms? 
Medical problems like a recent bout of upper respiratory tract infection and allergies are among the most common causes of hoarseness and should not be discounted immediately. Symptoms of hyperacidity are also significant. ${ }^{4}$

Is there a history of breathiness and difficulty of breathing? Voice fatigue, tremor, hypo or hypernasal voice? Choking, globus, odynophagia or dysphagia? Neck pain or head and neck trauma? These questions can give clues to the clinician regarding the possible cause of the problem.

\section{Past Medical History}

Asthma, COPD, pulmonary malignancy are associated with voice changes due to decreased airflow. Gastric ulcers and GERD can be suggestive of associated laryngopharyngeal reflux disease changing the vocal fold mucosa leading to voice change. ${ }^{3}$

Parkinsonism, myasthenia, traumatic brain injury and movement disorders can cause tremors, weakness or strained voice quality. Rheumatoid arthritis, SLE and other autoimmune disorders can cause voice changes such as paralysis in RA. Endocrine problems such as hypothyroidism can cause edema of the vocal folds leading to decrease in pitch. Thyroid cancer can cause vocal fold paralysis. A history of radiation secondary to malignancies in the head and neck can cause vocal fold scarring leading to voice change. ${ }^{1}$

Personality and psychiatric disorders also lead to diagnosis. The outgoing, type A personality usually has vocal fold nodules while inhibited and shy persons have functional dysphonias. ${ }^{5}$ Traumatic life events are also very important to take note of.

History of surgery for neck trauma, thyroid nodules or malignancies, spine, cardiac, pulmonary and brain surgeries or previous endotracheal intubation can cause voice changes, usually related to vocal fold mobility problems. ${ }^{1}$

Medications such as inhalational steroids for asthma can cause fungal laryngitis. ARB and ACE inhibitors for hypertension can cause non specific vocal fold masses. Antitussives, decongestants, antihistamines and Vitamin C are known to cause dryness of the vocal folds. Pills with sexual hormones can cause either elevations or decreases in pitch. ${ }^{6}$

Smoking can cause polypoid conditions in the vocal folds, premalignant or malignant changes. Intake of alcohol, diet and lifestyle can contribute to reflux problems and dysphonia.

\section{Physical Examination}

Hearing the patient and forming a subjective impression of the patient's voice should automatically be part of the interview process. Ranking the voice according to a standard scale is subjective but becomes increasingly reproducible and precise with training and experience.

Voice can be evaluated according to pitch, loudness and vocal quality.

Pitch is the highness or lowness of the voice. Is the speaking voice too low for the soprano? This could be the problem why a trained singer would have dysphonia. Does the woman sound like a man over the phone? This could be Reinke's edema, maybe she is a smoker as well.
Does the adult male suddenly speak with elevated pitch? This could be vocal fold paralysis.

Loudness is the power of the voice. This is due to the source of power, the lungs. Posture, type of breathing, technique or training can affect this. Systemic problems like generalized weakness and cachexia are contributory. Of course pulmonary problems can contribute to decreased power.

Voice quality can be evaluated using the GRBAS system. ${ }^{7}$ Just hearing the voice and using this system is helpful in making an impression.

G- grade

$\mathrm{R}$ - roughness

B- breathiness

A- asthenia

S- strain

GRBAS uses a 0 to 3 scale $(0=$ normal or absence of deviance; $1=$ slight deviance; $2=$ moderate deviance; $3=$ severe deviance).

Grade relates to the overall voice quality, integrating all deviant components

\begin{tabular}{l|l|l}
\multicolumn{1}{c|}{ GRBAS } & \multicolumn{1}{|c}{ Sounds } & \multicolumn{1}{c}{ Probable Conditions } \\
Roughness & Grainy quality; diplophonic & $\begin{array}{l}\text { Vocal fold masses such as nodules, polyps, cysts, } \\
\text { laryngitis }\end{array}$ \\
\hline Breathiness & Airy & $\begin{array}{l}\text { Unilateral paralysis, bowing, atrophy, abductor } \\
\text { spasmodic dysphonia }\end{array}$ \\
\hline Asthenia & No voice & $\begin{array}{l}\text { Bilateral paralysis in paramedian position, vocal fold } \\
\text { atrophy }\end{array}$ \\
\hline Strain & Tight quality & $\begin{array}{l}\text { Adductor spasmodic dysphonia, muscle tension } \\
\text { dysphonia }\end{array}$ \\
\hline
\end{tabular}

\section{Head and Neck Examination}

Palpating the neck, especially the base of the tongue and neck muscles which are tense and tender can be suggestive of an ongoing muscle tension dysphonia as a cause of the voice change. ${ }^{8}$ Thyroid masses, neck nodes, etc. can be helpful in leading the clinician to a diagnosis.

Visualizing the larynx has evolved as advances in technology have improved the understanding of vocal fold anatomy, physiology and voice production.

At present, there is no single laryngeal examination tool that is superior to the others. What is important is that it gives a thorough visualization of the anatomy and a good functional evaluation of the larynx. Selecting the appropriate instrumentation will be possible if we recognize the advantages and limitations of the diagnostic tool we are using. ${ }^{9}$ Sometimes, a combination of these tools is important to make an accurate diagnosis. 


\section{Advantages and Limitations of the Different Instruments to} Visualize the Larynx

\begin{tabular}{|c|c|c|}
\hline Instrument & Advantages & Limitations \\
\hline $\begin{array}{l}\text { Indirect Mirror } \\
\text { Laryngoscopy }\end{array}$ & $\begin{array}{l}\text { Readily available; } \\
\text { inexpensive } \\
\text { Gives a gross idea of the } \\
\text { anatomy; mobility; mucus; } \\
\text { and mass (if big enough) }\end{array}$ & $\begin{array}{l}\text { Limited in patients who are hypergag; patient is not in a } \\
\text { normal physiologic position; hard to detect paresis and } \\
\text { small lesions }\end{array}$ \\
\hline $\begin{array}{l}\text { Transnasal } \\
\text { Flexible } \\
\text { laryngoscopy }\end{array}$ & $\begin{array}{l}\text { Helpful for hypergag } \\
\text { patients; patients physiol- } \\
\text { ogy involving the tongue, } \\
\text { pharynx and palate are } \\
\text { well visualized; can assess } \\
\text { paresis from paralysis; can } \\
\text { be recorded for review }\end{array}$ & $\begin{array}{l}\text { Small lesions are hard to differentiate; color might not } \\
\text { be reliable depending on the camera; may be expensive }\end{array}$ \\
\hline $\begin{array}{l}\text { Rigid } 70 \text { or } \\
90 \text { degrees } \\
\text { laryngoscope }\end{array}$ & $\begin{array}{l}\text { Extremely clear and magni- } \\
\text { fied view; less expensive; } \\
\text { can be recorded for review }\end{array}$ & $\begin{array}{l}\text { Limited in patients who are hypergag; patient is not in a } \\
\text { normal physiologic position; hard to detect paresis and } \\
\text { muscle tension dysphonia }\end{array}$ \\
\hline $\begin{array}{l}\text { Videostrobos- } \\
\text { copy }^{10}\end{array}$ & $\begin{array}{l}\text { Provides a slow motion } \\
\text { evaluation of vocal fold } \\
\text { vibratory pattern, closure, } \\
\text { mucosal wave; can dif- } \\
\text { ferentiate benign vocal fold } \\
\text { lesions }\end{array}$ & Expensive; requires additional training \\
\hline
\end{tabular}

\section{Some helpful vocal tasks when using a flexible scope:}

\begin{tabular}{l|l}
\multicolumn{1}{c|}{ Task } & \multicolumn{1}{c}{ Endoscopic Findings } \\
/ii/ & Adduction \\
\hline Sniff & Abduction \\
\hline Hee-hee-hee & Either decreased adduction or abduction \\
\hline Sniff then /ii/ & Fatigues the vocal folds; detects paresis/ weakness \\
\hline $\begin{array}{l}\text { lii/ glide form } \\
\text { low to high pitch }\end{array}$ & ability to lengthen the vocal folds \\
\hline
\end{tabular}

Despite technological advances in laryngology, a good history and physical examination are still crucial in the diagnosis of voice disorders. Certain clues can be provided by a good history that especially point to a hoarse patient. Because no single instrument is superior for visualization of the larynx, it is important to recognize the advantages and limitations of each.

\section{REFERENCES}

1. Simpson CB, Fleming D. Medical and vocal history in the evaluation of dysphonia. Otolaryngol Clin N Am 2000; 33(4): 719-750.

2. Morrison MD, Rammage LA, Belisle GM. Muscular tension dysphonia. J Otolaryngol 1983; 12:302-306.

3. Koufman JA. The Otolaryngologic manifestations of gastroesophageal reflux disease (GERD): A clinical investigation of 225 patients using ambulatory 24-hour $\mathrm{pH}$ and an experimental investigation of the role of acid and pepsin in the development of laryngeal injury. Laryngoscope 1991; 101: 1-78.

4. Olson NR. Laryngeal manifestations of gastroesophageal reflux disease: Otolaryngol Clin N Am 1991; 24: 1201-1213.

5. Rosen DC, Sataloff RT. Psychology of Voice Disorders. 2006. San Diego (CA): Plural Publishing Inc. pp. 729-50.

6. Abaza Mm, Levy S, Hawkshaw M, Sataloff R. Effects of medications on voice. Otolaryngol Clin N Am 2007; 40:1081-1090.

7. Dejonckere PH. Perceptual and laboratory assessment of dysphonia. Otolaryngol Clin N Am 2000; 33(4): 731-49.

8. Sataloff RT, Hawkshaw M, Divi V, Heman-Ackah Y. Physical examination of voice professionals Otolaryngol Clin N Am 2007; 40: 953-69.

9. Rosen C, Murry T. Diagnostic laryngeal endoscopy. Otolaryngol Clin N Am 2000; 33(4): 751-57.

10. Kaszuba S, Garrett CG. Strobovideolaryngoscopy and laboratory voice evaluation. Otolaryngol Clin N Am 2007; 40: 991-1001. 